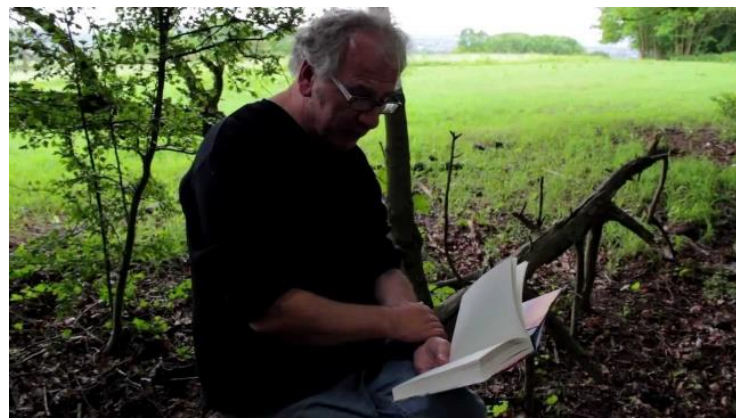

\title{
Interview with Nick Papadimitriou
}

\author{
Arup K. Chatterjee
}

Image: Courtesy Sceptre Books, from a reading of Scarp.

Nick Papadimitriou is a British author whose widely acclaimed novel Scarp was published in 2013. He is also the author of Foul Deeds and Suspicious Deaths in Barnet, Finchley and Hendon (2009). Papadimitriou designed the Middlesex County Council website in 2007, and in the same year he helped provide material for Will Self's The Book of Dave. In 2009, John Rogers made a film on Papadimitriou's life and thought, called The London Perambulator. From 2009 to 2011, along with Rogers, Papadimitriou hosted Ventures and Adventures in Topography, a radio show on Resonance FM. Papadimitriou calls his walks and writing 'deep topography', and is in turn described by his professional colleagues as a 'deep topographer', distinguishing his field of research and literature from ongoing trends of psychogeography.

This interview was conducted on a rainy afternoon, in a small café at Golders Green, near Hampstead Heath, in London.

AKC: As a biographical detail of the artist, what strikes one the most perhaps is the fact that you became the subject of the eponymous documentary filmed The London Perambulator, in 2011, even before your first major book Scarp. And even before the film was released, you had a very deep impact upon writers of space - say Will Self and lain Sinclair - who have quite seriously reflected upon your preoccupation with 'deep topography'. Both the authors describe you as an infectious character around whom one cannot but conceive a story. In other words, you have been seen as a personification of a lost Londoner and its deep topography. What really drove you to this unique pursuit of excavating extraordinarily intimate remains of London and perambulating them? Others have described deep topography as essentially more British than other contemporary concepts of space. How do you see your own theoretical child?

NP: There are a lot of answers I can give to those questions. For instance, there was a debatable situation after the first showing of The London Perambulator, where lain Sinclair said that I was a character from a Will Self book, and so he wanted to stay away from me, 
because he did not want to take a character from Self. But of course, I am NOT a character from a Self-book or a Sinclair-book. Much as I respect both these men - and indeed Self has been a very close friend for many years - I found the idea of being a character slightly irritating. Actually, I always found the idea of a film about me quite problematic. Since I would rather remove myself from the landscape, the environment, or the experiential field, that Self takes me through, I am never quite sure how to place meaningful parameters on where I am. My friends used to tell me, 'You are the interesting thing.' I do not believe that, for I think the world is really the interesting thing. Nobody would let me write about the world, rather they would only expect me to write about me. Maybe I am a particularly talented gymnast who refuses to do gymnastics, and wants to play football, instead. I find these personalities that one is given, as an author, highly problematic. For me, to move back to the human figure - what is my role? It is to move around. There is a phenomenological philosophy through Merleau-Ponty that the body is most crucial to draw itself perpetually back to the person, with his or her biographical detail.

AKC: The kind of work that you have done is different phenomenally from others in your league. It is one thing for an author to become all-important and appear on television shows, discuss political economy, and several things apart from literature. But it is quite another when the work cannot be separated from the author or the artist, in the first place. To me, your deep topography is not just $a$ writing but also an amassing of an archive of lost London. In that case it really can't be separated from you as a person, who wishes to be identified as a walking author.

NP: I realise it is difficult for people to do that, but it is not a primary interest to me. Having said that, Scarp has a lot of biographical detail. It is something I have struggled with enormously. The final section of Scarp is what purports to be a diary of a man named Perry Curland, but in fact I wrote it as an attempt to displace myself from the centre. I write through several characters in Scarp, in order to try and put myself out of the picture. I find a lot of the books broadly being published on psychogeography, in Britain, very uninteresting, actually. In fact, I do not read any, nor do I read Sinclair or Self on psychogeography. I have always preferred reading scientific ecological papers instead.

AKC: In Scarp, one comes across this deeply melancholy passage:

As the new arrives and is accommodated, the old is neglected, abandoned and then quietly killed off. There is a derelict 1920s fever-ward standing near the western edge of the hospital grounds between the 1970s nurses' flats and the obelisk celebrating the battle supposedly fought here between the Romans and the Catuvellauni in $54 \mathrm{BC}$. It is a long, low brick structure, with sun-bleached awnings hanging in rags from a steel frame mounted above its breeze-blocked entrance, and an off-white mock bell-tower perched on its pantiled roof. 
I would like to focus on these last few sentences - they exhibit a palpable interlacing of the slivers of time on a lost landscape. Is deep topography then amenable to historic atonements as well? In other words, would you say, space and time might only whisper together and not separately as in psychogeography or a hypothetical psycho-historiography? Scarp has been defined from within the dynamic of psychogeography or deep topography. But the novel has more of history than has really been talked about. There is a landscape of history of very intimate objects from everyday life, at times even scandalous things, which are not really scandalous in the larger scheme of affairs, but scandalous to everyday characters. It is a kind of archive from history. Can we actually separate the geography and the history or can they always whisper together only?

NP: Do they separate space and time in psychogeography? I think that knowledge can illuminate the thing that you have knowledge about. But in certain contexts, it can also interfere with knowledge of things. For instance, I may find a farming implement and not know what function it serves. If I asked you to walk off in a random direction until you collided with something - of course, taking into account your health and safety so you do not just walk into the road - what you think would happen when you finally collide? What would the experience be, supposing you collided with a lamp post? I am really interested about what happens in that time. For once, for a better way of looking at it, you could be pulled out of your instrumental mode of interaction with the world and face the facts as far as we can define it. There are actually real things around us, not just symbolic ones. Another thing that can happen in that experiment is that when you hit the lamppost, it is ripped out of your purely instrumental relationship in a very physical way, where the lamp post is two inches from your nose. You know how hard the metal is, suddenly the lamp post is liberated from its instrumentality, and becomes sculpturesque, or far richer in detail.

\section{AKC: Does it also become an adversary in some cases?}

NP: These things are stopping us all the time, while we just keep hitting them. If you hit a little hawthorn bush and you might get probably a touchy-feely natural thing, where you think of all the hundreds of hawthorn bushes you walked past. I can intellectualise but it is always tentative. The intellectualising is always a surplus, to some extent. Partly because a vicious dialectic is established whereby in order to topographise properly, you have to surrender to the larger field you are encountering outside yourself. It is a very quick journey from there to interpreting what you've experienced through a mastery over the thing, where it came from acknowledging that the experiential field is bigger than you. That's one of the reasons why I am always worried about theory. I worry it will inadvertently close the range of possible experiences.

AKC: Your prose has been described as mellow or even angelic and is much at odds with the esoteric vocabulary of theorists of psychogeography. Have you ever felt like there was a dis- 
junction between theories and your own topographical work? Was there anything in theories or ideas of psychogeography, flâneurie, or the dérive, that appealed to you and you imbibed?

NP: I have to get my developmental history in place which means introducing some biography. I trained as a therapist in the late 1980s. I felt burned out, and through instinct that was when I first consciously started walking. I am not really a London writer. I am more interested in the edge-effect - in the various ages of London and in the beginnings of rural non-London. When I started walking in the peripheries, I did not really quite know why except I was very hurt and angry. It was my way of gaining mastery over defining myself with a larger current than the one that went along with the people around me. I began to notice after a while that during these walks, I ended up with a magnitude of experience that did not sound like the rambler's associations - the people who go walking in the countryside, for instance. Mine were strange, very intense experiences, due to the sheer magnitude of hyperparticularities that I engaged with on the walk, and a sense of traversing the landscape and carrying pain with it sometimes. I started to call that 'deep topography', because I was still a young man who wanted to make some kind of mark on the world. No one had heard of Sinclair or Self that time. Now that everyone talks about psychogeography, I get a bit fed up with it, sometimes. I am not sure if anyone has a fixed half-definition of how psychogeography works, or if it is actually a discipline. In that sense, I suppose, I have the unequivocal legal right to call what I do 'deep topography'. I am not sure there would be any difference apart from the incidental ones. Maybe if there were two deep topographers, things would become complicated. l'd probably want to beat up the other claimant.

As regards theory, I was disdainful towards it. I found a lot of it over-voluptuous, in the French way. I do not think I am a sort of meat-and-potatoes English philosopher saying that I can take poetic license in philosophy, and I can take a degree of pretension; sometimes even that becomes a vital ingredient. Perhaps Guy Debord was pulling our leg when he said that people went on really long dérives, driving him insane. His focus on de-familiarisation, and the way he spoke about disorientation, was a template for me to analyse what goes on in my deep topography, and communicate it. I've been given some good practical groundwork by Debord. But besides that, I am very much my own man.

I am not sure where the activity we are talking about - be it psychogeography, or deep topography - actually happens. My inclination is therefore to go for something we can be specific about and say, the sine qua non is walking. We are talking about gaining knowledge of where we've walked, bringing knowledge into where we've walked, generating cultural products, interacting with other cultural products about the places. Once I woke up at $\mathbf{3}$ in the morning with a panic attack because I realised I did not know what psychogeography was, and the university was paying $₫ 3000$ each month to train students in that subject. When I told this to my students, everyone looked worried. For me there is an existential component to walking. I am on the surface of the planet, when I am walking. I look at my conditions very much - and our conditions - in a way that's not reflected into a room where a drama or a song is happening, where a broken heart is grieving or a poem where a poet has to wrap 
everything up to actually make it all rather nice ... or a film perhaps. But walking out of culture - consumable artistic culture - is the most important aspect of my theory.

I think the amnesia of where we come from is very inter-generational and extremely rapid. I went out to Poland and worked for the Polish Navy in the early 1990s. The Wall had come down two years before. I was very interested in Polish poets for freedom like Cheswaf Mewash and Zbigniew Herbert who wrote in Samizdat. The 16- to 17-year-olds I met in Poland at that time - two years after the wall came down - did not care about any of that stuff. It was something their parents had done. It was as remote for them as ballroom dancing was for me in the 1960s with my parents. And this was two years after they had been given the freedom for which their parents had fought. If you grow up in the world you take it as it is given to you. It takes a lot of experience to see that there are deeper momentums at play, Putin for instance, and the deep legacy of the Second World War and the Russian experience. We did very little and they did most and is indeed to some extent a highly valid view. The kind of nostalgia and patriotism that we have for our Battle of Britain and Dunkirk, compare that with what are they entitled to in terms of their mythos about the Second World War ...

AKC: From the history of the personal and the political, let us move to the public sphere. Of all public institutions of the past or the present, the railways are woven indiscriminately into natural surroundings of London as well as its rich and complex architecture. Can you recount your experience of encountering the railways as part of urban life and the life of your topographical explorations?

NP: The railways enabled me to get to new bounds around the margins of London, and that's at the most prosaic level. I also see the railways as ecological corridors, so when you are looking at railways in a suburban or urban context what you have is a striation of the rural needling into London. That's an interesting and destabilising concept.

A very interesting walk to do is to go to the London Bridge. I learned of it from an old 'Countess of Britain' series that was published in the early 1950s. There is one book about South London, where the author attacks South London for basically being a dump. One of the things the author points out is that running eastwards from London Bridge Station are over a thousand arches carrying the railways across these successive river valleys that are feeding into the Thames. It is a really interesting thing to go and have a look at because that's an extensive piece of brick engineering running about 3 miles across London. Was 'Scarp' actually effectively invisible? My interest is in that invisibility. Ideology makes things invisible as we know, and so does instrumentality. Cars are effectively invisible for us a lot of the time aren't they? I am very bothered by invisibility, by the way things are invisibilised. Walking is an extremely effective way of doing things visibly, and revisibilising things around us.

AKC: London is historically a city of what the French philosopher Jacques Derrida describes - in a very different context however - as hantology. Where Derrida talks about the spectre 
haunting Europe, he means the spectre of communism, and also the spectres from the great Shakespearean tragedies. Has London haunted you in real or metaphorical ways? There seem to be a few supernatural beings lurking in Scarp. What would you say of their genesis?

NP: The sub-sections in Scarp are really attempts at integrating a trans-temporal and transpersonal way with the experiential field. The experiential field of Scarp is like an ecosystem that is always fraying out in its own edge-effects. There are two immortal characters - the serial killer, John Osborne, and Merrops, the crow. It was an attempt to see things perhaps under the aspect of eternity to study whether that would throw into relief some of those deeper mementos that have gone unnoticed in our world.

AKC: A continuum between what has been and what is now! The deeper momentum as you say can only be visible through the body and the eyes of somebody who's been across the ages. Which is what you mean by yogic or tantric?

NP: There are the two eternal characters whom I have used as de-familiarising devices. Then there is Gloria Geddes, a member of the psychedelic ancients of Middle-Saxony. She uses yoga, sex and drugs in order to experience what she calls Prakriti Laya, a yogic term, meaning fusion with nature. It has been described as a lesser Samadhi, where the subject and the object are fused but not in the more profound sense when you fuse with a Godhead or the world. Because I can't conceive a more transcendental world, it was a device for me in order to try and write outside of human and non-human experience, and also outside the usual signatures of time and space. Still, within a relatively discrete realm, Gloria Geddes becomes a hornet for a season. I have a dismal feeling that it probably comes from English Romanticism. I am not really a culture person. I am mainly reading books about the Second World War. One comes to see that the Indian army was woefully underrepresented in British histories.

AKC: Your literature and even your walking belongs in various states of practical and workable philosophies of daily life. Can you give us some insights into your philosophical or spiritual process?

NP: I've had my 15 minutes of relative fame and l've been forgotten in the psychogeography world - or so it seems. I've had writer's block for a long time. Scarp was a difficult act to follow, I must admit. But l've got some pieces of experimental poetry being published. Also I'd like to write about the Liridona Method. The Liridona Method is named after a student of ours, Liridona Oxa, who told us last year that her project would be to walk in a straight line until she collided with something. She gave me the idea for a Zen-type slap around the face. I am really interested in what happens, and I am intent upon analysing what happens when people move in a straight line and collide with something. Because what happened with me was that the students turned around and glared at me. 
AKC: Perhaps, on a prosaic level, it is the lack of instrumentality that really bothered them. I too was bothered when you described it, and was beginning to explore the reasons why someone would feel that way. I do not think it is subversive, really, but it is a kind of poetry which has not been explored and explained, not been packaged well in a paperback form.

NP: If I over-explained, it would interfere with the experience. I want them to come back to me because I need to experience some identification of what happens to me when I do that. I am not sure what relationship this would have with anything else I have done. But it is to me a foundational consideration. When I first started walking - about three decades ago - the first thing I did was to link traces of historic English culture. It is astonishing how the world has changed in that time. The first thing I linked up with was the rolling countryside Englishesque, Edward Elgar, Shakespeare, these green and pleasant pastures. But that did not particularly work for me in the long run because I felt like I was being spoon-fed by a memory of culture. I went through a Celtic hippie period where the land was full of kind of mysteries of Dakinis, as you would call them in India - the spirits in the trees and wells. Again, I felt that it was interfering with my perception and my own processes. I was getting too much of a package that was explaining everything to me. Then I went through a yogic phase, ending in a nervous breakdown. I realised if one wanted to have a Samadhi, one should not be too worried about the hyper-particularities of your environment, because they are eventually dross. What was more of interest to me was the notion that Maya which was akin to nothing - not an illusion like a virtual world that we keep creating in our minds. Maya began to seem more like the ideology and instrumentality of things that interfere with the way we see them.

When I used to do yoga, I went to the Shiva Nanda Yoga Centre in Barnes, where everyone was very Indian, accompanied by their Indian Ragas. In the end, I did not know what relationship I was getting into with what category or discipline - Indians or yoga or Hinduism. Anyhow, a lot of the yogic talk of 'whatever will be will be' did not quite add to my wisdom any more than just being a reminder of what I have known.

Arup K. Chatterjee is Assistant Professor of English at the Jindal Global Law School. At the time of this interview, he was a visiting fellow at the Brunel University, London. In 2014, he was a recipient of the Charles Wallace fellowship to United Kingdom. He received his doctorate from the Center for English Studies, Jawaharlal Nehru University, New Delhi, for his dissertation titled: 'Hillmaking: Architecture and Literature from the Doon Valley.' He is the Founder Chief Editor of Coldnoon: International Journal of Travel Writing \& Travelling Cultures, and author of the widely reviewed The Purveyors of Destiny: A Cultural Biography of the Indian Railways (Bloomsbury, 2017). He has contributed numerous articles on history, literature, culture and politics, to magazines such as The Conversation, Scroll, The Hindu, The Wire, DailyO, Huffington Post, and The Caravan, as well as Coldnoon.

An Interview with Nick Papadimitriou. Arup K. Chatterjee. Writers in Conversation Vol. 5 no. 2, August 2018. journals.flinders.edu.au 